\title{
Snapping scapula syndrome: current concepts review in conservative and surgical treatment
}

\author{
Giovanni Merolla \\ Simone Cerciello \\ Paolo Paladini \\ Giuseppe Porcellini
}

Unit of Shoulder and Elbow Surgery

Biomechanics laboratory "Marco Simoncelli"

D. Cervesi Hospital, Cattolica, Italy

Corresponding author:

Giovanni Merolla

Unit of Shoulder and Elbow Surgery

Biomechanics laboratory "Marco Simoncelli"

D. Cervesi Hospital,

Via L. V. Beethoven, 46

47841 Cattolica, Italy

e-mail: giovanni.merolla@ausIrn.net

\section{Summary}

The snapping scapula, also called "washboard syndrome" is a controversial condition attributed to bony and soft tissue abnormalities. The syndrome was understimated for long time and often associated only with specific osseous abnormalities. The nodal point in the overview of the syndrome is that crepitus associated with symptomatic bursitis may be physiologic and is not uncommon a clinical presentation without any form of crepitus or craquement. In the current rewiew we analyzed the current concepts in the conservative and surgical management of snapping scapula syndrome, preceded by a description of scapular anatomy, pathophysiology of scapulothoracic articulation and clinical features of snapping scapula.

KEY WORDS: scapula, snapping, conservative treatment, open surgery, arthroscopy.

\section{Introduction}

Disorders of the scapulo-thoracic joint, including bursitis and crepitus, are commonly misdiagnosed problems. Boinet ${ }^{1}$ in 1867 was the first surgeon to describe scapulo-thoracic crepitus. Later Mauclaire ${ }^{2}$ identified three subclasses: 1) "froissement", which was the physiologic friction sound, 2) "frotting" which was a louder grating sound often associated with pathologic alterations, 3) "craquement" which was a pathologic loud snapping sound. Similarly, Milch ${ }^{3}$ and $\mathrm{Kuhn}^{4}$ discerned loud and painful grating sounds (craquement) caused by osseous anomalies, and gentle and less intense sounds (frotting) caused by soft tissues problems. However, an exact distinction of "snapping scapula" etiology is often difficult to establish, furthermore, conventional radiology is useful for the diagnosis, but is not always exhaustive to identify the origin; for these reasons is not rare that the diagnosis is confirmed during the operative procedure. The nodal point in the overview of the syndrome is that symptomatic bursitis may arise without any crepitus, as well as painless crepitus may be physiologic. Scapular dyskinesis is another condition that can be associated with bone or bursal anomalies and therefore need to be recognized and treated. It leads to alterations in the static scapular position and loss of dynamic control of scapular motion ${ }^{5}$ such as increase in anterior tilt, a decrease in scapular upward rotation, and an increase in scapular internal rotation. The anteriorly tilted scapula compresses the medial border against the ribs, and the scapula pivots around its medial border rather than sliding laterally. Alterations of the bony morphology of the scapula or ribs include scapular exostoses, such as Luschka's tubercle, malunion of scapular fractures, Sprengel's deformity, and healing rib fractures ${ }^{3,6,7}$. In this paper we analyze the current concepts in the conservative and surgical management of snapping scapula syndrome, preceded by a description of scapular anatomy, pathophysiology of scapulo-thoracic articulation and clinical features of snapping scapula.

\section{Scapular anatomy}

The scapula is a triangular-shaped bone, which articulates with the posterior chest wall. It is in conjunction with the upper limb by only the acromioclavicular joint, and therefore its stability is dependent on surrounding musculature ${ }^{8}$. The elevator scapulae and rhomboids attach to the medial border of the scapula, whereas the subscapularis originates form its anterior surface ${ }^{4,9}$. The serratus anterior originates from the ribs and inserts on the medial aspect of the scapular anterior surface. Thus subscapularis and serratus anterior create a sort of cushion between posterior chest wall and anterior scapular surface, 10-12.

Two anatomic spaces are then identified: the subscapularis space and the serratus anterior space. The former is located between the chest wall, serratus anterior, and rhomboids; the latter is bounded by 


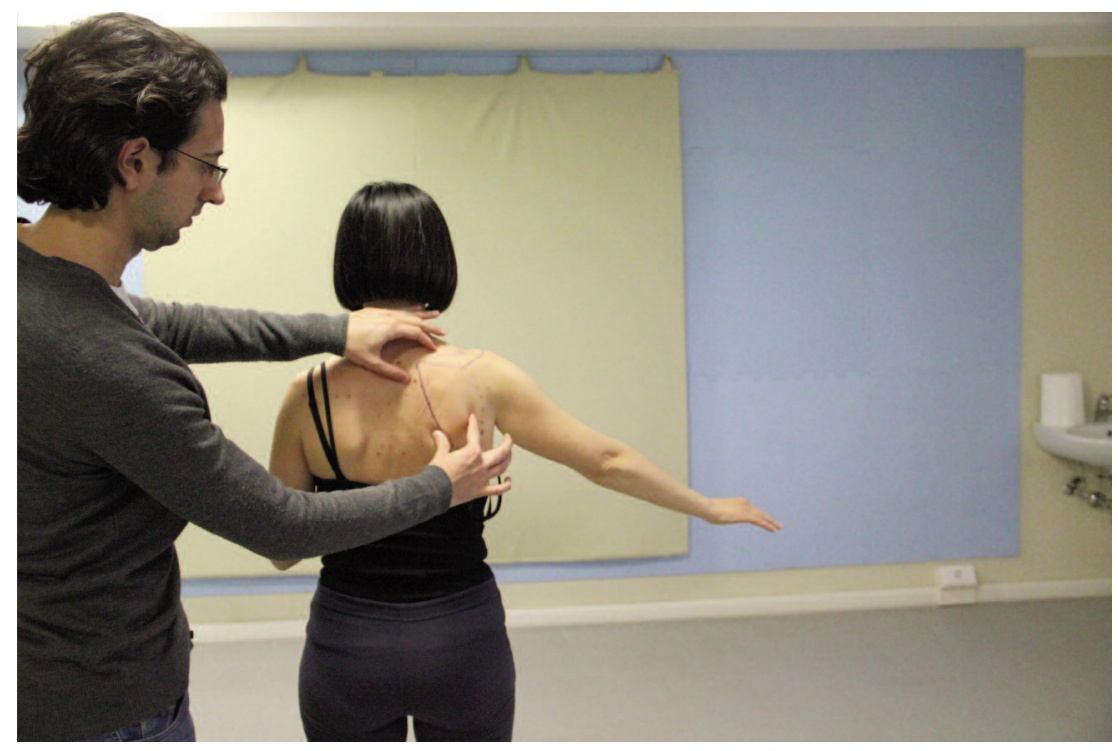

Figure 1. During arm abduction the physician can feel the crepitus and hear the snapping.

the serratus anterior, subscapularis, and axil$\mathrm{l}^{6,11,13,14}$. Finally three out of the four muscles of the rotator cuff originate at the scapula: the supraspinatus and the infraspinatus from the posterior surface of the scapula and the subscapularis on the anterior surface.

Several bursae have been described which are situated in areas where increased friction may occur and are virtual spaces filled by a synovial membrane ${ }^{9}$. Kuhn et al. ${ }^{4}$ described two major and four minor bursae in this joint. The first major bursa is located between the serratus anterior muscle and the chest wall (scapulothoracic or infraserratus bursa), while the second is situated between the subscapularis and the serratus anterior muscles (subscapularis or supraserratus bursa) (Fig. 1). Anatomical research findings showed the two major bursae were also found in cases whereas each of the four minor bursae were absent ${ }^{4}$. Biomechanics abnormalities of the scapulathoracic joint may lead to symptomatic inflammation of these bursae. Finally, there are several neurovascular structures surrounding the scapula. The accessory nerve goes through the elevator scapulae muscle close to the superomedial angle of the scapula and runs along the medial scapular border deep to the trapezius muscle ${ }^{11}$.

The transverse cervical artery branches anastomose into the dorsal scapular artery (deep branch) and suprascapular artery, with a superficial branch that flows with the accessory nerve. The dorsal scapular artery flows with the dorsal scapular nerve $1 \mathrm{~cm}$ medial to the medial border of the scapula. This rich collateral arterial circle pierce the scalenus medius and travel deep to the rhomboid major and minor. The scalenus medius is innervated by the branches of cervical and brachial plexus (C3-C7), while the dorsal scapular nerve provide the innervations of rhomboids muscles. The long thoracic nerve is located on the surface of the serratus anterior. The suprascapular nerve and artery run toward the suprascapular notch on the superior scapular border medial to the base of the coracoid $6,11,13,15$.

\section{Pathophysiology}

Snapping of the deep surface of the scapula may be painful or painless. It is the consequence of bony alterations, or inflamed soft tissues such as bursae. The less-protected superior, medial, and inferior aspects of the scapula are more affected by soft-tissue abnormalities, such as muscle insertion avulsions, which can produce spur scar formation ${ }^{16}$, and inflamed, thickened, painful bursa, which can result from forceful repetitive stresses between the anterior surface of the scapula and the underlying musculature and rib cage ${ }^{17}$. Scapular diskinesis may aggravate both of these conditions aggravating clinical presentation.

Three trigger points have described for these inflamed burse: the superomedial angle of the scapula (supraserratus or infraserratus bursa), the inferior angle of the scapula (infraserratus bursa) and the medial base of the spine of the scapula underlying the trapezius muscle (trapezoid bursa) (Fig. 1).

\section{Clinical presentation}

Patients often refer history of pain during overhead activities or repetitive overuse of the shoulder, or even a single traumatic injury $4,8,15,18-20$; typically they describe an audible and palpable crepitus with active shoulder movements, including shrugging of shoulders $^{21,22}$. These symptoms may result from participation in sports activities, including swimming and 


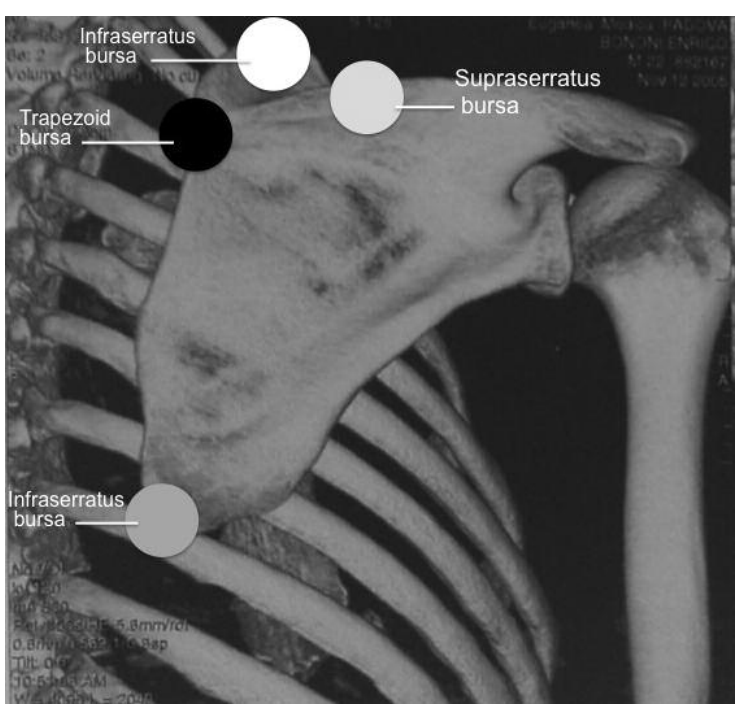

Figure 2. Schematic representation of major and minor bursae of the scapulothoracic joint.

throwing, or from other rapid overhead arm movements ${ }^{18,23,24}$. Although the audible symptoms can be painless, it is common that pain is present and may be severe enough to limit most of daily activities. The location of the pain is mostly at the supero-medial angle or inferior pole of the scapula and sometimes an additional cervical irradiation can be referred ${ }^{13,25,26}$. Under clinical evaluation, the physician can feel crepitus and hear the snapping in most patients. The crepitus is easily reproduced during arm movement because pain occurs generally with shoulder abduction (Fig. 2). The crepitus may be accentuated with the compression of the superior angle of the scapula against the chest wall during arm abduction ${ }^{27}$. Most of patients com- monly have tenderness to palpation at the supero-medial border or inferior pole of the scapula8,18. Due to muscle contracture and malfunction, patients can also claim pain at the palpation over the levator scapulae, trapezius, and/or rhomboid muscles. Pain is normally not reproducible with isometric movements ${ }^{21,22}$. Pain and snapping generally decrease crossing the arm, thus lifting the scapula from the ribcage ${ }^{10}$. The evaluation of scapular motion is crucial. When scapular asymmetry is detected, it can be the result of a scapular dyskinesis or underlying mass or space-occupying lesion. However pseudo-winging may be present as the patient compensates for pain ${ }^{18,24}$ (Fig. 3). Scapulo-thoracic bursitis generally cause deep pain at the level of levator scapulae and the supero-medial angle of the scapula. Trapezoid bursitis is a rare cause of more superficial pain, referred over the junction of the spine and the medial border 25 .

\section{Conservative treatment}

Conservative treatment aims to correct muscles dysfunction, postural factors and scapular dyskinesis 8,28 . However, since the major causes leading to the onset of snapping scapula are overuse and improper joint mechanics, initially the patient have to change his activities and rest the joint to calm the cycle of bursitis and scarring. Thus a course of nonsteroidal anti-inflammatory medications is indicated to decrease inflammation 4,18 that can associated with additional conventional treatments including ice, heat, and ultrasound treatments. Other researchers suggested the use of diathermy, ultrasound, and iontophoresis to the undersurface at the medial border of the scapu$\mathrm{Ia}^{29}$. After that pain is alleviated with the aforementioned physical treatments, patients can be directed to a standard program of physiotherapy. Muscle im-

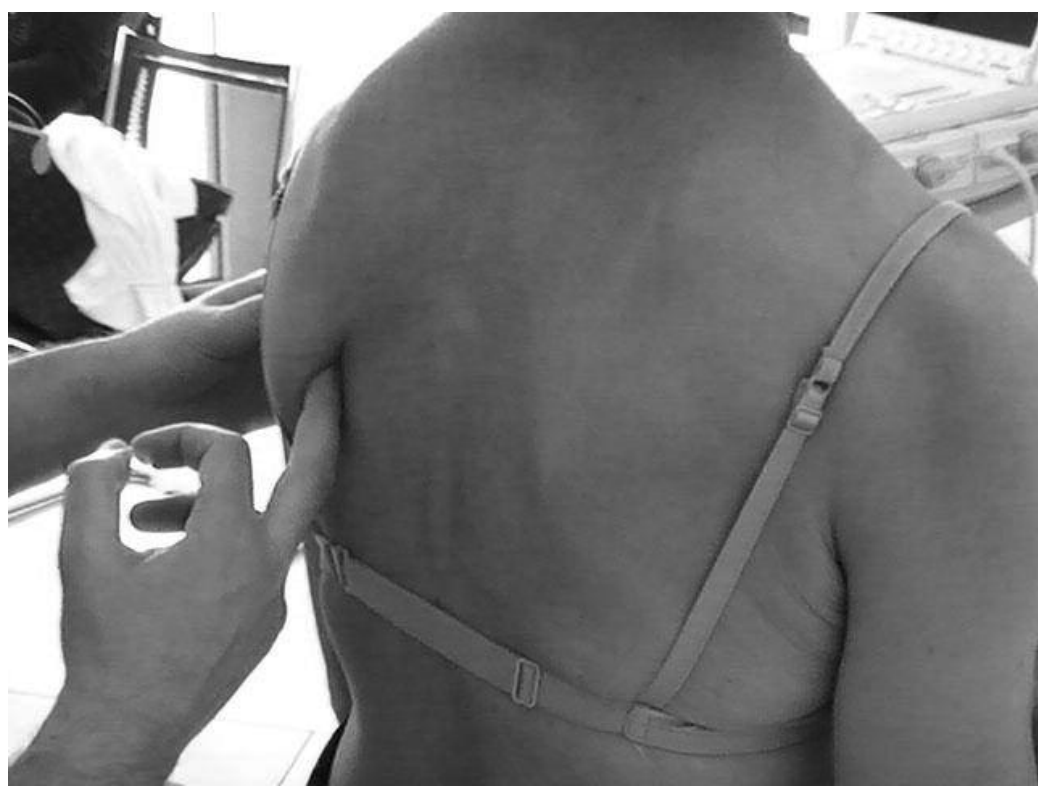

Figure 3. Pseudo-winging of the scapula may be a way by which the patient may compensate the pain. 

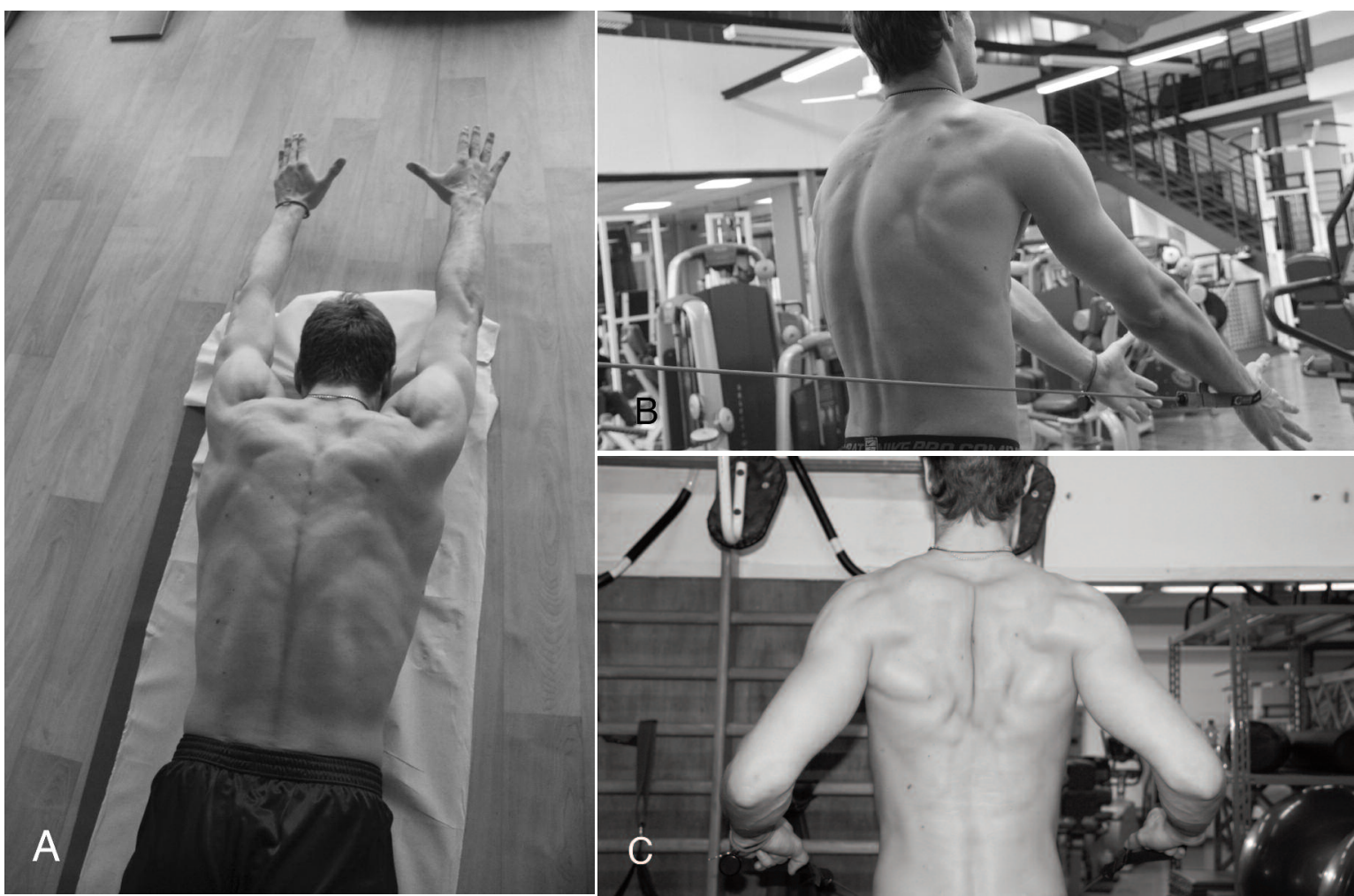

Figure 4. Exercises for scapular muscles rehabilitation (A), lower trapezius (B), anterior dentatus, $(C)$, rhomboids.

balance should be corrected, strengthening weak muscles and stretching antagonist retracted ones. Abnormal posture or winging scapula must be addressed in order to restore proper joint mechanics. It is supposed that when scapulothoracic crepitus is related to soft tissue abnormalities, altered posture, scapular winging, or scapulothoracic dyskinesia, surgical intervention will not be required ${ }^{30}$. Muscular stretching and strengthening and postural training are the most beneficial treatments. Postural training aims to minimize kyphosis, promote upright posture, and strengthen upper thoracic muscles. Thoracic kyphosis is associated with forward head, rounded shoulders, abducted and forward-tipped scapulae ${ }^{31}$ and sub-occipital extension ${ }^{32}$. The tightened muscles include pectoralis major and minor, levator scapulae, upper trapezius, latissimus dorsi, subscapularis, sternocleidomastoid, rectus capitis, and scalene muscles. Weakened muscles include the rhomboids, mid and lower trapezius, serratus anterior, teres minor, infraspinatus, posterior deltoid, and longus colli or longus capitis. Restoring scapular strength establishes static proximal stability to provide a stable base of support ${ }^{33}$. Because the scapula is responsible for static stability of the shoulder girdle, endurance training of these muscles is the key for scapular stability. This type of training necessitates low-intensity, high-repetition exercises. Strengthening of the subscapularis and serratus anterior are crucial since a weak serratus anterior muscle causes forward tilting of the scapula inducing crepitus ${ }^{34,35}$. Scapular adduction and shoulder shrug exercises strengthen scapular stabilizers (serratus anterior, rhomboids, levator scapulae) that provide the correct scapula position $6,36,37$ (Fig. 4A-C). On the contrary, abduction and elevation of the scapula should be avoided because cause increased pressure and strain on the underlying musculature ${ }^{8}$. All these exercises aim to resolve muscle imbalance and correct scapular motion thus reducing pain and functional impairment. Implementation of the rehabilitation program should be comprehensive. It is important the strengthening of the core or trunk of the body (the core is defined as the lumbopelvic-hip complex $)^{38}$, because it serves as the crossroads for energy transfer in all human movement, where the forces can move from the lower to the upper extremities or vice versa ${ }^{39}$. However if pain persists, physical therapy must be avoided and local injection of anesthetics and steroids have to be considered $4,18,19,40$. The technique for scapulothoracic injection is performed on the patient prone, with the shoulder in extension, internal rotation, and adduction and the hand that lies behind the back ("chicken-wing position") 25,36 (Fig. 5). The needle (1.5-inch 22-to 25gauge) is inserted parallel to the anterior border of the scapula, taking care not to penetrate so deep as to cause a pneumothorax. When the pain is referred at the inferior angle of the scapula, the needle is entered and directed laterally on the infero-medial border of the scapula. For the supero-medial bursa, the 


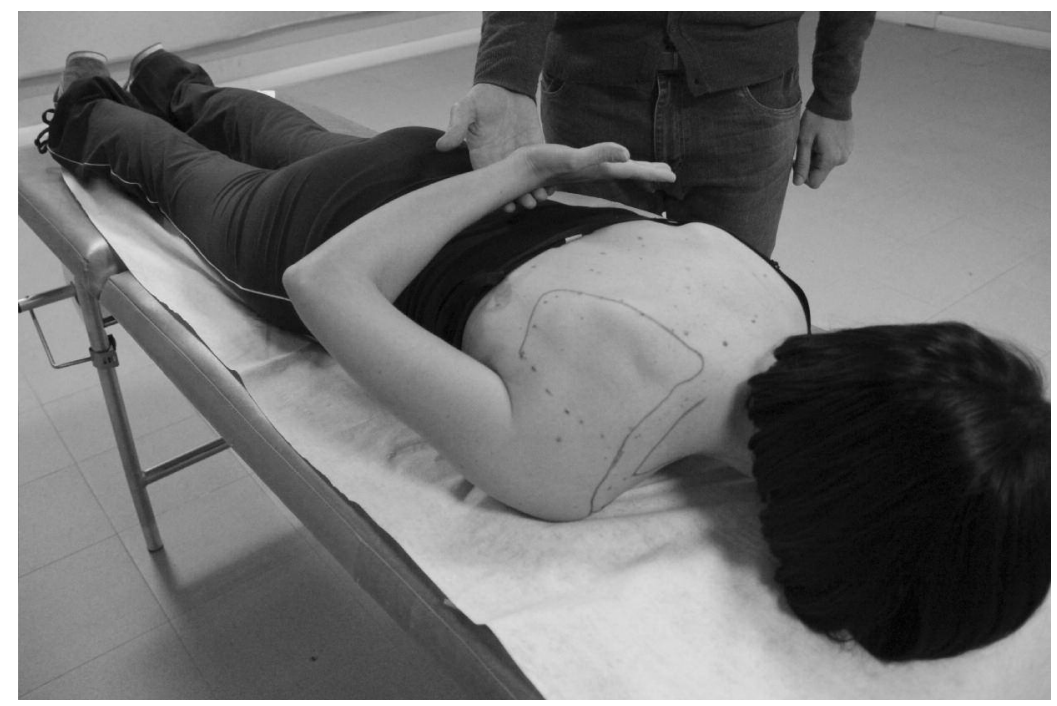

Figure 5. "Chicken-wing position": the hand is behind the back and the shoulder is extended and internally rotated to lift away the medial border of the scapula from the thoracic cage.

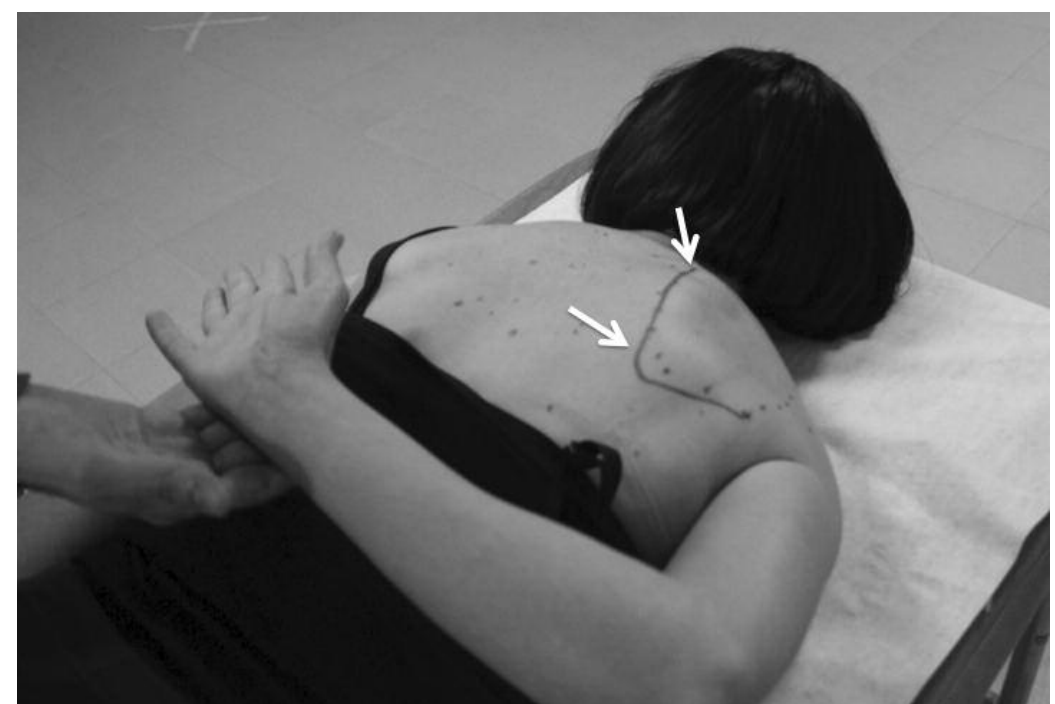

Figure 6. Superomedial and inferomedial sites for scapulothoracic injections (white arrows).

needle should be angled $45^{\circ}$ laterally going from proximal to distal and entering just off the superiormedial tip of the scapula6,8 (Fig. 6). Corticosteroid injections are usually repetead from 3 to 4 times per year ${ }^{4}$; furthermore, the combination of local anesthetic with steroids injection can be considered as a dignostic test that give a high likelihood that scapular bursitis or crepitus is related to the patient's pain when is followed by partial or complete pain relief ${ }^{9}$. If all non-surgical measures fail to relieve the symptoms after 3 to 6 months, surgical options should be considered.

\section{Surgical treatment: procedures and results}

Surgical procedure should be undertaken when conservative treatment has not been effective in resolving pain and improve shoulder function. Indications for surgery must be carefully evaluated using the aforementioned clinical and radiographic criteria, excluding patients with cervical spine disorders and neurological impairment ${ }^{41}$. Failure to have pain relief after a preoperative injection of anesthetic in the superomedial or inferomedial scapular angle, exactly in the site where the patient localize the pain, may be a contraindication to operative management ${ }^{41}$. Operative treatment for snapping scapula was first described by Milch in $1950^{3}$, who performed the procedure in local anesthesia asking the patient to identify the site of the scapula to be resected. Additional research findings showed good clinical results after open approach for bursectomy and partial resection of the superior or inferior scapular angle 10,12,42-45. Surgery is commonly performed with the patient in lateral decubitus or preferably in prone position, with the arm internally rotated to lift away the medial border of the scapula from the thoracic cage ${ }^{14}$ (Fig. 7). 


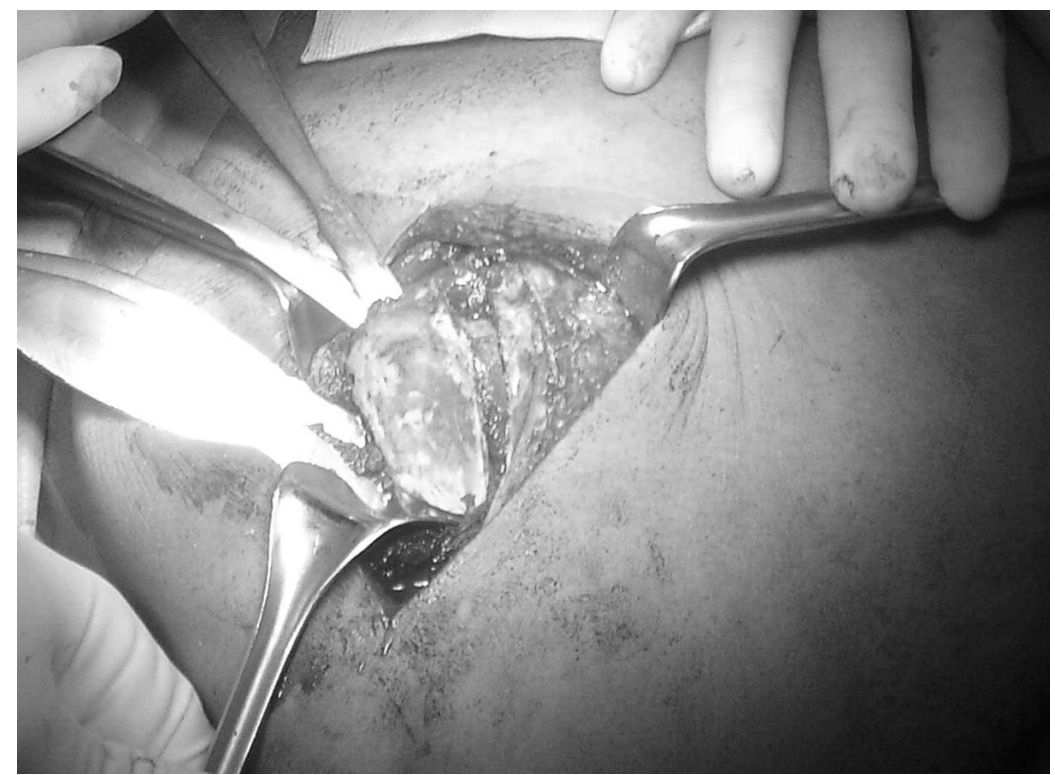

Figure 7. Open surgical approach. The patients is placed in prone decubitus, after muscles detachment the scapula is elevated from the ribs using the Hohmann retractor and the arm has been turned in neutral rotation before to resect the supeormedial tip of the scapula.

Recently, Ross et al. ${ }^{46}$ have described a surgical approach on the patient in beach chair position with a spider device used to assist with protraction of the scapula. Anatomical landmark are drawn and the incision is located along the medial border of the scapula, subsequently we split the upper trapezius from the scapular spine to expose the superior angle of the scapula, taking care to identify and protect the spinal accessory nerve along the superior scapular edge laterally to the superomedial angle and levator scapu$\operatorname{lae}^{47,48}$. At this stage of the procedure, levator scapulae and rhomboids muscles must be detached or preferentially released subperiosteally to completely expose the anteromedial border of the scapula and having the tendinous insertions preserved and free to be reattached to their anatomical origin ${ }^{43}$. The structure at risk during rhomboids detachment is the dorsal scapular nerve which is medially located, at an average distance of $2 \mathrm{~cm}$ from the medial scapular border $^{41}$. The bone surface of the scapula is now adequately exposed to isolate and resect the pathological bursa, spurs or other osseous abnormalities (Fig. 7 ). At the end of the procedure rhomboids muscles are reattached with bone drill holes and the wound is closed in layers using absorbable sutures ${ }^{43}$. The arm is protected in a sling for 4 weeks followed by a standard program of physiotherapy including exercises for the restoration of the range of motion and muscle strengthening. Several studies reported good to satisfactory results after open treatment of snapping scapula 17,34,49,50. Specifically, McCluskey and Bigliani ${ }^{50}$ described the results of isolated bursectomy at the superior scapular angle (supraserratus bursa) as satisfactory in six cases and good in two cases, while the last case was complicated by spinal nerve accessory palsy who underwent to additional intervention for tendon transfer with poor long-term benefit. Sisto DJ et al. ${ }^{17}$ reported that all 4 pitchers treated with open bursectomy of the inferior angle of the scapula (infraserratus bursa) had relief from pain and associated symptoms and returned to the same preoperative level in their sport activity. In a large case series of 17 patients treated with open procedure for scapulothoracic pain, Nicholson and Duckworth $^{43}$ reported satisfactory outcomes in all cases and in addition to the bursectomy they performed the resection of the supero-medial scapular angle in 5 out 17 cases and explored the scapulotrapezial bursa. Histological examination of the resected soft and bone tissues showed chronic inflammation and physiological bone architecture ${ }^{17,43,50}$. Arthroscopy is a valid technically demanding alternative to conventional open approach in the treatment of symptomatic snapping scapula. Due to its low invasiveness, arthroscopic surgery guarantee several advantages compared with open procedure, such as decrease morbidity for preservation of muscles attachment, early postoperative rehabilitation and return to full function, good cosmesis, short hospital stays and higher patient's compliance ${ }^{14,18,51}$. Scapulothoracic arthroscopy was initially described with 2 medial scapular portals ${ }^{14}$, subsequently was added a third superior portal ("Bell's portal") 15,19,36 (Fig. 8). The procedure is performed on the patient in prone or lateral position with skin landmark drawn and the arm internally rotated, as described for the open surgical procedure ("chicken-wing position") 25,52,36 (Fig. 8). We begin by creating the two medial portals, the first is for the view at the level of the scapular spine, the second is a working portal located inferior to the spine $^{14,15,36,40}$ (Fig. 8). Since the restricted space to work, a spinal needle placed at the superomedial corner of the scapula can assist in orientation ${ }^{19,25}$. We establish the upper medial portal, $3 \mathrm{~cm}$ medial to the spine of the scapula and we introduce the trocar through the skin to pass: 1) trapezius, 2) the plane 


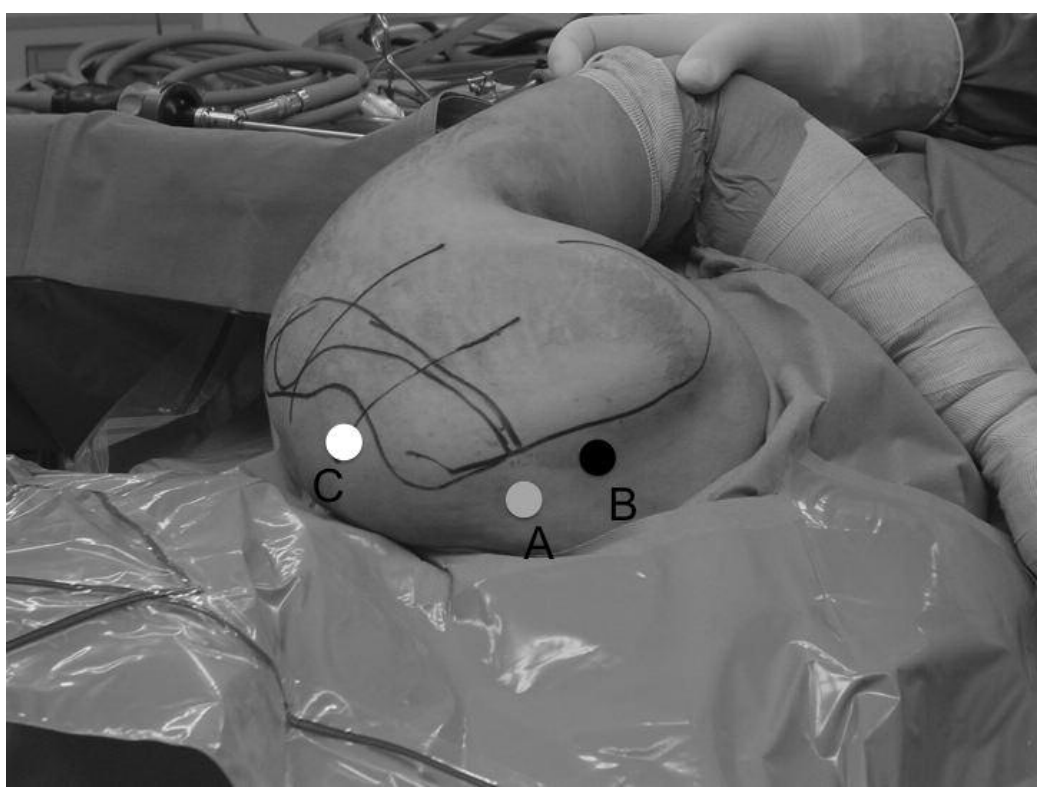

Figure 8. Patient position in lateral decubitus for arthroscopic procedure. Arm in "chicken-wing position", skin landmarks show the scapula contours and sites (circles) for the three arthroscopic portals: superomedial $(A)$, inferomedial (B) and superior (C) ("Bell's portal").

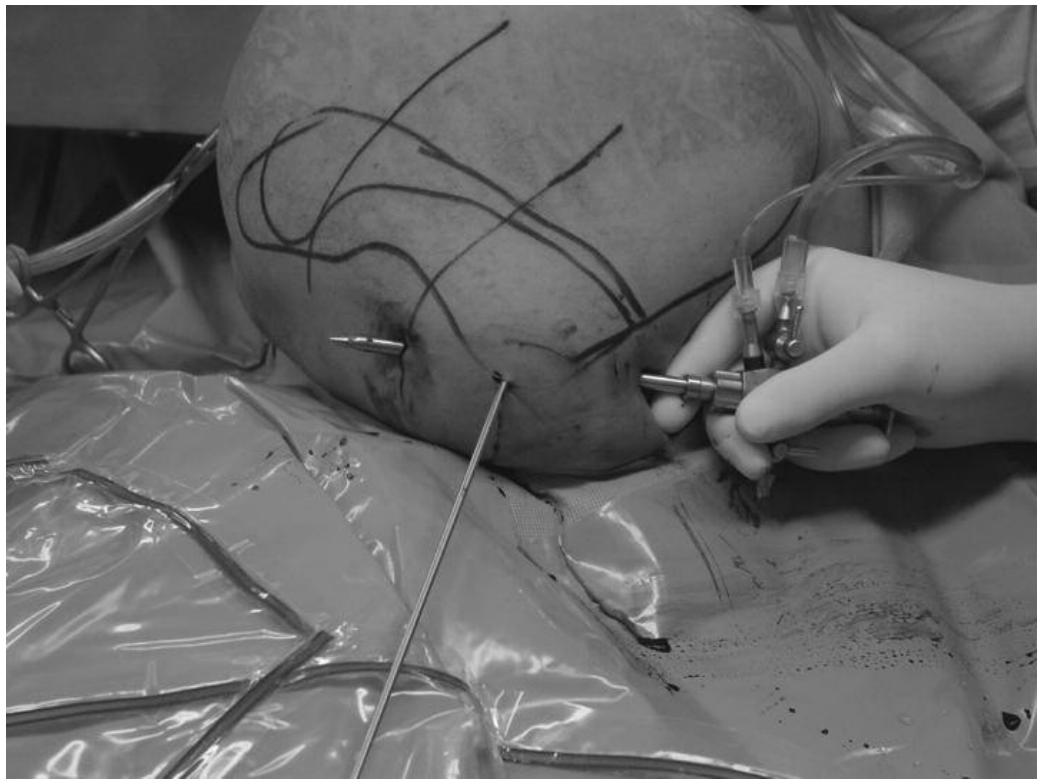

Figure 9. Inside-out technique to create the superior Bell's portal.

between rhomboid major and minor, 3) serratus anterior space. During this early phase the operator must be careful not to force the introducer in the chest wall, running a risk to cause a pneumothorax or to perforate the serratus until to enter the axillary space ${ }^{11,14,18}$. Under the arthroscopic visualization we create the inferior medial portal in the midway between the scapular spine and the inferomedial scapular angle ${ }^{14,48}$ When we use this portal to work in the subscapularis space, the instruments should point away from the coracoid process to reduce the risk of suprascapular nerve injury ${ }^{11}$. The third superior portal is extremely useful, especially when the scapulothoracic bursectomy is associated with the resection of the superomedial angle of the scapula; it is created following two bony landmarks, the superomedial angle of the scapula and the lateral border of the acromion, the position is located between the middle and medial thirds of the line joining these two points ${ }^{36}$ (Fig. 9). The aforementioned anatomical sites of entry must be respected to avoid damage to the neurovascular structures ${ }^{15,19,36}$; moreover, when the trocar is passed through the third portal, is mandatory to be as close as possible to the ventral surface of the scapula to avoid the penetration of the thoracic cavity ${ }^{15,19,36}$. Alternatively the superior third portal can be created using an inside-out technique, starting with the arthroscope in the viewing portal that is directed superiorly from the scapulothoracic space just laterally to the point marked with a needle and exit in the pre- 


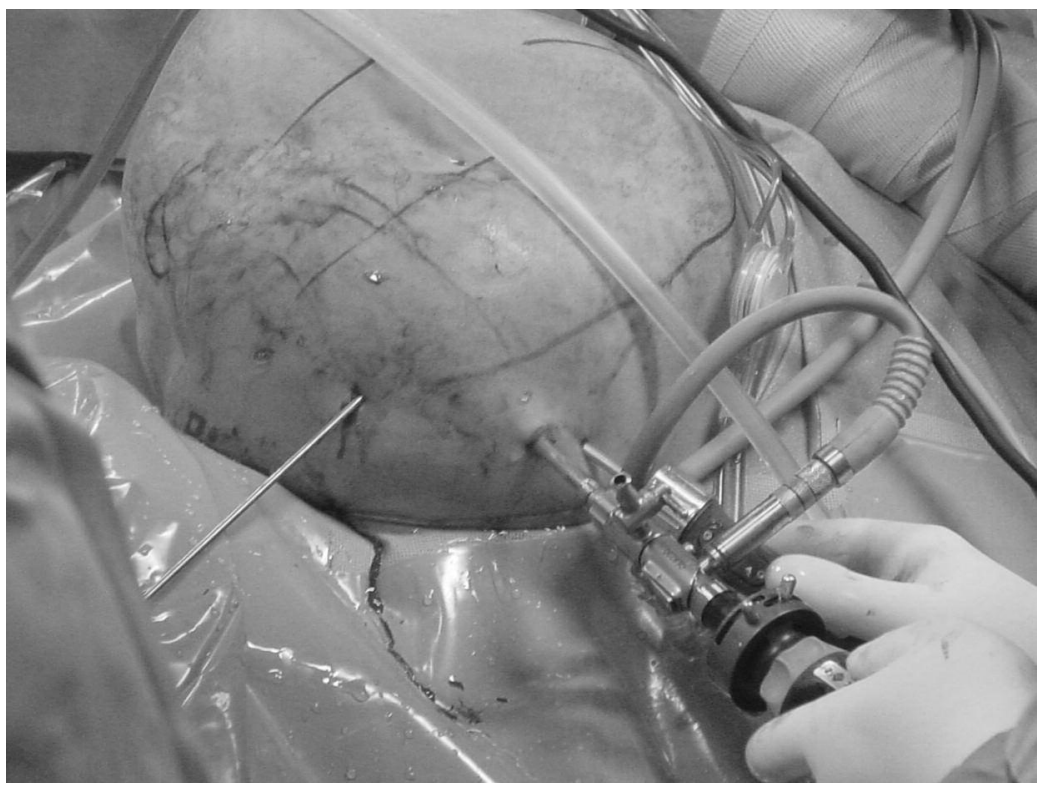

Figure 10. Operative arthroscopic step. The arthroscope is in the "viewing portal" (superomedial) and the shawer in the "working portal" (inferomedial) to carry out the procedure on soft and bony structures. A smooth-end instrument ("Wissinger rod technique") is placed at the supero-medial corner of the scapula to assist in orientation.

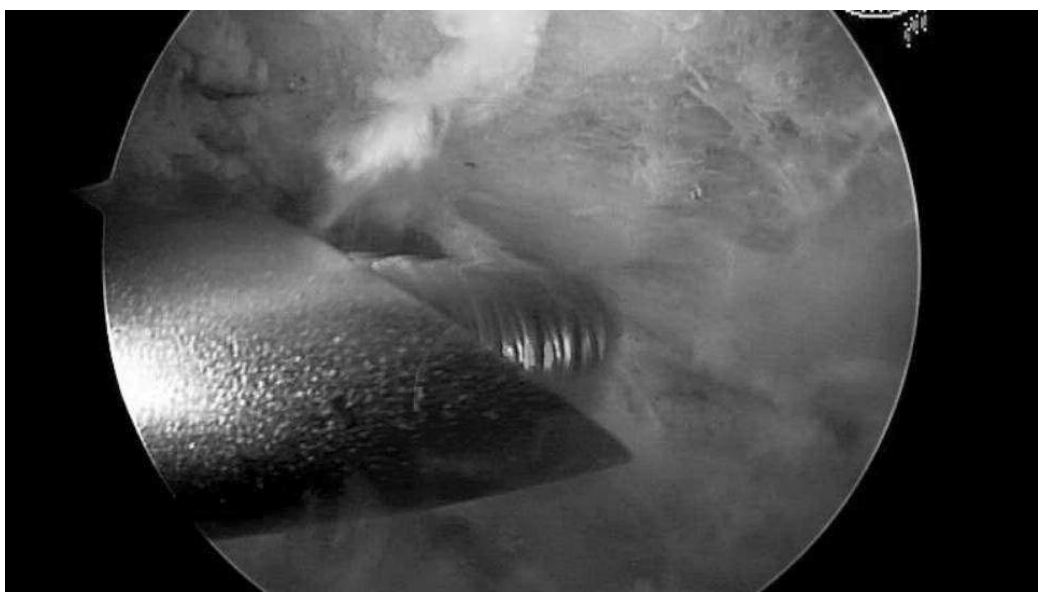

Figure 11. Intraoperative arthroscopic findings showing the motorized shawer in the scapulothoracic space while removes the infraserratus bursae and expose the superomedial corner of the scapula.

viously marked region corresponding to the superior portal (Fig. 9). The procedure go on with the arthroscope $\left(30^{\circ}, 4.5 \mathrm{~mm}\right)$ introduced in the portal of viewing using a fluid pressure of $50-60 \mathrm{~mm} \mathrm{Hg}$ to the scapulothoracic space (Fig. 10). From the inferior working portal or from the superior third portal instruments are introduced to carry out the procedure on soft and bone structures (Fig. 10); bleeding is controlled with radiofrequency device and fibrous tissues are removed with a shaver to find the subscapularis bursa (supraserratus bursa). Supraserratus and infraserratus bursae and any fibrous adhesions all around are removed until to expose the superomedial angle of the scapula (Fig. 11). If preoperative planned spur resection is confirmed by intraoperative surgeon assessment of superomedial angle prominence, the last step is the resection of a superomedial corner of the scapula together with a little amount of the superficial cortex of the scapula. This step should be considered complete when the corner is flat compared with the rest of the scapula ${ }^{36}$ and the arm movement do not determine impingement of this area on the deeper structures ${ }^{40}$. The superior portal has been measured to be at a minimum distance of $12 \mathrm{~mm}$ from the suprascapular nerve ${ }^{15}$, that is considered safe for portal placement but not a safe distance from the suprascapular notch when we work with a shawer or burr in the scapulothoracic articulation ${ }^{19}$. In order to reduce the risk of suprascapular nerve damage, Bell and van $\operatorname{Riet}^{53}$ suggest to direct the shawer from the Bell portal ${ }^{19}$ toward a target that is a skin landmark equidistant between the inferior corner of the scapula and the scapular spine (Fig. 12). In this way they found a minimum distance of $25 \mathrm{~mm}$ between the resected bony edge and the nerve compared with a 10 $\mathrm{mm}$ distance when the shawer was directed to the inferior corner of the scapula.

Finally the wound is sutured and the arm is protect in 


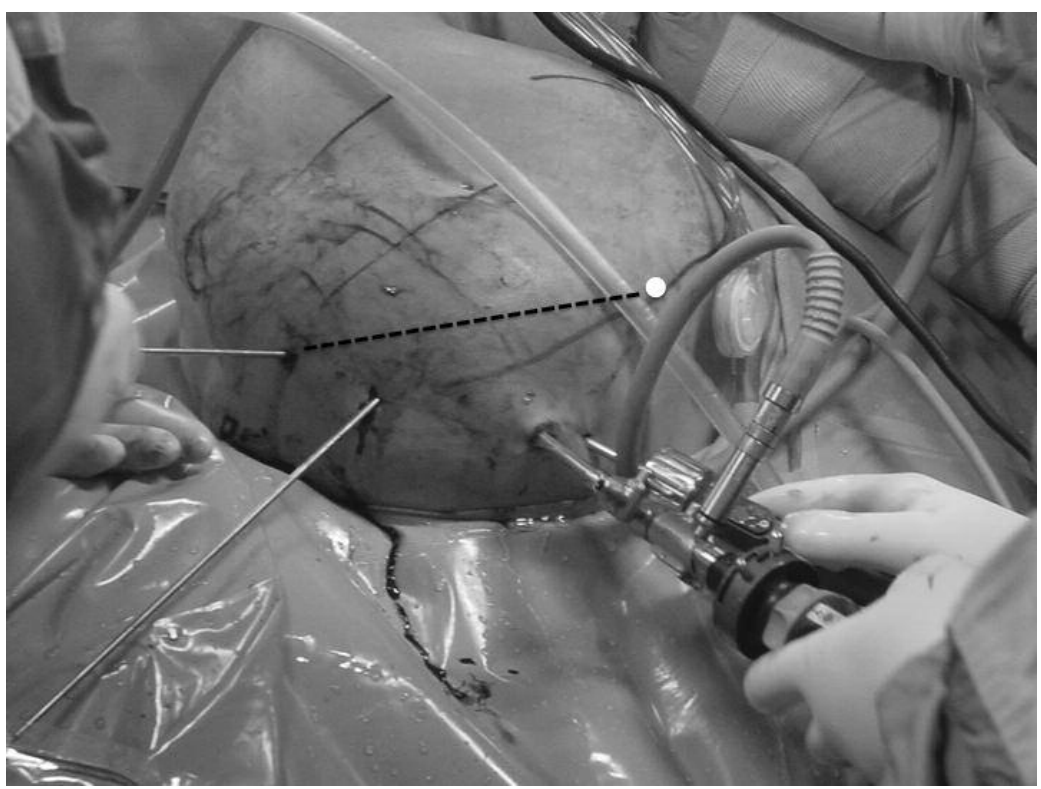

Figure 12. Operative athroscopic step. The arthroscope, the shawer and the Wissinger rod are placed as described in the Fig. 11. To perform a safe superomedial bone resection, an additional Wissinger rod is introduced in the superior Bell's portal and directed toward a target (dotted line) that is equidistant between the inferior corner of the scapula and the scapular spine (white circle).

a sling. Passive mobilization begin the first postoperative day, the full active range of motion is achieved within 1-2 weeks, cautious strenghtening exercises are allowed after 30 days; the patients can return to their sports activity the third postoperative month.

Most case series studies on arthroscopic approach for snapping scapula reported good to excellent results ${ }^{14,29,36,40}$. Blønd and Rechter ${ }^{54}$ in a prospective follow-up study on twenty patients at 2.9 years after arthroscopic scapular bony resection, reported an increase of the median Western Ontario Rotator Cuff Index score from 35 to 86 ; furthermore, 19 out of 20 patients indicated that they would undergo the surgery again. Millett et al. ${ }^{25}$ in a retrospective study on 22 patients at a minimum of 2 years follow-up, treated with arthroscopic bursectomy and partial scapulectomy, reported a postoperative improvement of 20 points in ASES score, a Quick DASH score of 35 pints and a single assessment numeric evaluation (SANE) shoulder score of 73 points; the authors concluded that although significant pain and functional improvement can be expected after arthroscopic bursectomy and scapuloplasty, the average postoperative ASES and SANE scores remained lower than expected. Pavlik et al. ${ }^{36}$ describing the results of a prospective study on ten patients underwent to scapulothoracic arthroscopy, reported that UCLA score at an average follow-up of 11.5 months, was excellent in 4, good in 5 and fair in 1; the authors concluded that the procedure was beneficial in the majority of the patients and highlighted the role of the superior portal to make the procedure easier to perform. Pearse et al. ${ }^{40}$ in a retrospective case series study on thirteen patients, reported that 9 patients had an improvement in their symptoms with median Constant score of 87 points, while 4 felt that their symptoms were unchanged or worse with a median Constant score of 55 points; 8 out of 9 employed pa- tients returned to their previous careers and 6 out of 9 patients who played sports returned to their preoperative level of sporting activity. It was interesting to note that bone was resected from the superomedial angle only if it appeared to be prominent during arthroscopy and this occurred only in 3 cases. Lien $\mathrm{SB}$ et al. ${ }^{55}$ described a combined method using endoscopic bursectomy with mini-open partial scapulectomy for treating 12 cases of snapping scapula and reported a significant postoperative improvement in ASES score and Simple Shoulder Test, the snapping sound and pain improved in 10 out of 12 cases and all subjects returned to work.

\section{Overview}

The snapping scapula, also called "washboard syndrome"56, "scapulothoracic syndrome" 57 or "scapulocostal syndrome" 58 is a controversial condition attributed to bony and soft tissue abnormalities. The syndrome was understimated for long time and often associated only with specific osseous abnormalities such as tumor (i.e osteochondroma) ${ }^{51,59}$, exostoses $^{12,60}$, malunion of rib and scapular fractures ${ }^{61}$, because the radiographic imaging has not been able to trace back to the primary cause of the condition without any of the aforementioned skeletal lesions. Rarely, an abnormal angulation of the superior angle of the scapula can produce a symptomatic snapping scapula ${ }^{42}$. When the syndrome is correctly diagnosed and the source of scapulothoracic crepitus is ascribable to soft tissue disorder, altered posture and scapular winging or dyskinesis, the first approach should be non-operative $29,30,50$. The treatment consists of rest, nonsteroidal anti-inflammatory drugs and shoulder rehabilitation. The planned rehabilitation program should be multifactorial, focusing on posture, 
strength, and endurance ${ }^{31,62,63}$. Injection of corticosteroid and local anesthetics is also a viable option as diagnostic and therapeutic goal ${ }^{41}$. Operative treatment is undertaken when non surgical measures fail. After the initial good results of open surgical procedures in the last 10 years become established arthroscopic techniques due to the low invasiveness, good cosmesis and early recovery, especially in professional sportsmen. To date, the outcomes of arthroscopic management are described in case series studies with short-term follow-up and cases that failed have been attributed to patient selection and technical difficulties ${ }^{14,29,36,40}$. We think that further cohort studies investigating surgical vs conservative interventions or comparing arthroscopic and open procedures can help to set the best treatment option for snapping scapula syndrome.

\section{References}

1. Boinet $W$. Bulletin de la Societe Imperiale de Chirurgie dr Paris. 2nd ser. 1867; 8:458.

2. Mauclaire M. Craquements sous-scapulaires pathologiques traits par l'interposition musculaire interscapulothoracique. Bull Mem Soc Chir Paris 1904; 30:164-168.

3. Milch H. Partial scapulectomy for snapping of the scapula J Bone Joint Surg Am 1950; 32-A:561-566.

4. Kuhn JE, Plancher KD, Hawkins RJ. Symptomatic scapulothoracic crepitus and bursitis. J Am Acad Orthop Surg 1998; 6:267-273.

5. Kibler WB, McMullen J. Scapular dyskinesis and its relation to shoulder pain. J Am Acad Orthop Surg 2003; 11:142-151.

6. Butters KP. The scapula. In: Rockwood CA, Jr, Matsen FA III, eds. The shoulder. Philadelphia: Saunders, 1990:335-366.

7. Alvik I. Snapping scapula and Sprengel's deformity. Acta Orthop Scand 1959; 29:10-15.

8. Manske RC, Reiman MP. Nonoperative and operative management of snapping scapula. Am J Sports Med 2004 32:1554-1565.

9. Percy EC, Birbrager D, Pitt MJ. Snapping scapula: A review of the literature and presentation of 14 patients. Can J Surg 1988; 31:248-250.

10. Carlson HL, Haig AJ, Stewart DC. Snapping scapula syndrome: Three case reports and an analysis of the literature. Arch Phys Med Rehabil 1997; 78:506-511.

11. Ruland LJ III, Ruland CM, Matthews LS. Scapulothoracic anatomy for the arthroscopist. Arthroscopy 1995; 11:52-56.

12. Parsons TA. The snapping scapula and subscapular exostoses. J Bone Joint Surg Br 1973; 55:345-349.

13. Lesprit E, Le Huec JC, Moinard M, Schaeverbeke T, Chauveaux D. Snapping scapula syndrome: Conservative and surgical treatment. Eur J Orthop Surg Traumatol 2001; 11:5154

14. Harper GD, Mcllroy S, Bayley JI, Calvert PT. Arthroscopic partial resection of the scapula for snapping scapula: A new technique. J Shoulder Elbow Surg 1999; 8:53-57.

15. Chan BK, Chakrabarti AJ, Bell SN. An alternative portal for scapulothoracic arthroscopy. J Shoulder Elbow Surg 2002; 11:235-238.

16. Strizak AM, Cowen MH. The snapping scapula syndrome. A case report. J Bone Joint Surg Am 1982; 64:941-942.

17. Sisto DJ, Jobe FW. The operative treatment of scapulothoracic bursitis in professional pitchers. Am J Sports Med 1986 14:192-194

18. O'Holleran JD, Millett PJ, Warner JJP. Arthroscopic man- agement of scapulothoracic disorders. In: Miller MD, Cole BD, eds. Textbook of arthroscopy. Ed 3. Philadelphia: Saunders, 2004:277-287.

19. VanRiet RP, Bell SN. Scapulothoracic arthroscopy. Tech Shoulder Elbow Surg 2006; 7:143-146.

20. Lintner D, Noonan TJ, Kibler WB. Injury patterns and biomechanics of the athlete's shoulder. Clin Sports Med 2008; 27:527-551.

21. Kouvalchouk JF. Subscapular crepitus. Orthop Trans 1985; 9:587-588.

22. Cobey MC. The rolling scapula. Clin Orthop Relat Res 1968 ; 60:193-194

23. McFarland EG, Tanaka MJ, Papp DF. Examination of the shoulder in the overhead and throwing athlete. Clin Sports Med 2008; 27:553-578.

24. Kuhn JE. In: lannotti JP, Williams GR, eds. The scapulothoracic articulation: Anatomy, biomechanics, pathophysiology and management. Philadelphia: Lippincott Williams \& Wilkins, 1999: 817-845.

25. Millett PJ, Pacheco IH, Gobezie R, Warner JJP. Management of recalcitrant scapulothoracic bursitis: Endoscopic scapulothoracic bursectomy and scapuloplasty. Tech Shoulder Elbow Surg 2006; 7:200-205.

26. Edelson JG. Variations in the anatomy of the scapula with reference to the snapping scapula. Clin Orthop Relat Res 1996; 322:111-115.

27. Milch H. Partial scapulectomy for snapping of the scapula J Bone Joint Surg Am 1962; 44:1696-1697.

28. Tripp BL. Principles of restoring function and sensorimotor control in patients with shoulder dysfunction. Clin Sports Med 2008; 27:507-519

29. Ciullo JV, Jones E. Subscapular bursitis: conservative and endoscopic treatment of "snapping scapula" or "washboard syndrome." Orthop Trans 1993; 16:740.

30. McClusky GM, Bigliani L. Scapulothoracic disorders. In: Andrews JR, Wilk KE, eds. The Athlete's Shoulder. New York, NY: Churchill Livingston; 1994:305-316.

31. Kisner C, Colby LA. Therapeutic Exercise: Foundation and Techniques. 4th ed. Philadelphia, Pa: FA Davis; 2002.

32. Janda V. Muscles and cervicogenic pain syndromes. In: Grant $\mathrm{R}$, ed. Physical Therapy of the Cervical and Thoracic Spine. New York, NY: Churchill Livingstone; 1988:153-166.

33. Knott M, Voss D. Proprioceptive Neuromuscular Facilitation. New York, NY: Harper and Row; 1968.

34. Arntz CT, Matsen FA. Partial scapulectomy for disabling scapulothoracic snapping. Orthop Trans 1990;14:252-253.

35. Lehman GJ, Gilas D, Patel U. An unstable support surface does not increase scapulothoracic stabilizing muscle activity during push up and push up plus exercises. Man Ther 2008; 13:500-506

36. Pavlik A, Ang K, Coghlan J, Bell S. Arthroscopic treatment of painful snapping of the scapula by using a new superior portal. Arthroscopy 2003; 19:608-612.

37. Safran MR. Management of scapulothoracic problems. Curr Opin Orthop 1997; 8:67-74.

38. Dominguez RH, Gajda R. Total Body Training. East Dundee, III: Moving Force Systems; 1982.

39. Dintman G, Ward B, Tellez T. Sports Speed. Champaign, III: Human Kinetics; 1997.

40. Pearse EO, Bruguera J, Massoud SN, Sforza G, Copeland SA, Levy O. Arthroscopic management of the painful snapping scapula. Arthroscopy 2006; 22:755-761.

41. Lehtinen JT, Macy JC, Cassinelli E, Warner JJ. The painful scapulothoracic articulation: surgical management. Clin Orthop Relat Res 2004; 423:99-105.

42. Oizumi N, Suenaga N, Minami A. Snapping scapula caused by abnormal angulation of the superior angle of the scapula. J Should Elb Surg 2004; 13:115-118. 
43. Nicholson GP, Duckworth MA. Scapulothoracic bursectomy for snapping scapula syndrome. J Shoulder Elbow Surg 2002; 11:80-85.

44. Cameron HU. Snapping scapulae: a report of three cases. Eur J Rheumatol Inflamm 1984; 7:66-67.

45. Morse BJ, Ebraheim NA, Jackson WT. Partial scapulectomy for snapping scapula syndrome. Orthop Rev 1993; 22:1141-1144.

46. Ross AE, Owens BD, DeBerardino TM. Open scapula resection in beach-chair position for treatment of snapping scapula. Am J Orthop (Belle Mead NJ) 2009; 38:249-251.

47. Williams GR Jr, Shakil M, KItmkiewicz J, lannotti JP. Anatomy of the scapulothoracic articulation. Clin Orthop Relat Res 1999; 359:237-246.

48. Lazar MA, Kwon YW, Rokito AS. Snapping scapula syndrome. J Bone Joint Surg Am 2009; 91:2251-2262.

49. Richards RR, McKee MD. Treatment of painful scapulothoracic crepitus by resection of the superomedial angle of the scapula. A report of three cases. Clin Orthop Relat Res 1989; 247:111-116.

50. McCluskey GM III, Bigliani LU. Surgical management of refractory scapulothoracic bursitis. Orthop Trans 1991; 15:801.

51. Fukunaga S, Futani H, Yoshiya S. Endoscopically assisted resection of a scapular osteochondroma causing snapping scapula syndrome. World J Surg Oncol 2007; 5:37.

52. Kuhne M, Boniquit N, Ghodadra N, Romeo AA, Provencher MT. The snapping scapula: diagnosis and treatment. Arthroscopy 2009; 25:1298-1311.

53. Bell SN, van Riet RP. Safe zone for arthroscopic resection of the superomedial scapular border in the treatment of snapping scapula syndrome. J Shoulder Elbow Surg 2008; 17:647-649.

54. Lars Blønd, Simone Rechter. Arthroscopir treatment for snapping scapula: a prospective case series. Eur J Orthop Surg Traumatol 2013 Jan 5.

55. Lien SB, Shen PH, Lee CH, Lin LC. effect of endoscopic bursectomy with mini-open partial scapulectomy on snapping scapula syndrome. J Surg Res 2008; 150:236-242.

56. Cohen JA. Multiple congenital anomalies: the association of seven defects including multiple exostoses, von Willebrand's disease, and bilateral winged scapula. Arch Intern Med 1972; 129:972-974.

57. Moseley HF. Shoulder Lesions. 2nd ed. New York, NY: Hocher; 1933.

58. Shull JR. Scapulocostal syndrome: clinical aspects. South Med J 1969; 62:956-959.

59. Kwon OS, Kelly Jl. Delayed presentation of osteochondroma on the ventral surface of the scapula. Int J Shoulder Surg 2012; 6:61-63.

60. Girard J, Laffargue P, Migaud H, Boutry N. Rev Chir Orthop Reparatrice Appar Mot 2003; 89:449-452.

61. Takahara K, Uchiyama S, Nakagawa H, Kamimura M, Ohashi M, Miyasaka T. Snapping scapula syndrome due to malunion of rib fractures: a case report. J Shoulder Elbow Surg 2004; 13:95-98.

62. Michele AA, Davies JJ, Krueger FJ, Lichtor JM. Scapulocostal symdrome (fatigue-postural paradox). N Y State J Med 1950; 50:1353-1356

63. Moseley JB, Jobe FW, Pink M, Perry J, Tibone J. EMG analysis of the scapular muscles during a shoulder rehabilitation program. Am J Sports Med 1992; 20:128-134. 